\title{
PRODUÇÃO DE VÍDEOS ESTUDANTIS PARA UMA EDUCAÇÃO INOVADORA EM TEMPOS DE PANDEMIA
}

\author{
Valter Moreira Durães ${ }^{1}$ \\ Cristiane Prando Parizotto ${ }^{2}$ \\ Deikimar Antonio Lima ${ }^{3}$ \\ Vanessa Wegner Agostini ${ }^{4}$
}

\begin{abstract}
RESUMO: Com a pandemia do Coronavírus, a educação encarou um paradigma crucial concernente aos métodos pedagógicos. Soma-se a isso a necessidade de estabelecer estratégias de ensino que oportunizem um aprendizado ativo. Desse modo, o objetivo desse relato de experiência foi avaliar a relevância da produção de vídeos estudantis como método inovador de aprendizagem. A intervenção pedagógica foi realizada em uma escola pública com alunos de 8 ㅇ e 9 을 anos do ensino fundamental II, de maneira on-line. A proposta baseou-se na junção das ferramentas metodológicas de Storytelling, Stop motion e produção de vídeos estudantis. Foram realizados quatro encontros na disciplina de História, com a temática da Segunda Guerra Mundial. Os alunos demonstraram maior domínio dos objetos de aprendizagem após a produção e apresentação dos vídeos, constatados pela análise dos trabalhos desenvolvidos por eles e do questionário avaliativo.
\end{abstract}

Palavras-chave: Métodos Pedagógicos. Aprendizagem. Escola Pública. História.

\section{PRODUCTION OF STUDENT VIDEOS FOR INNOVATIVE EDUCATION IN TIMES OF PANDEMIC}

ABSTRACT: With the coronavirus pandemic, education faced a crucial paradigma concerning pedagogical methods. Added to this is the need to establish teaching strategies that provide opportunities for active learning. Thus the objective of this experience report was to evaluate the relevance of student video production as an innovative learning method. The pedagogical intervention was carried out in a public

\footnotetext{
${ }^{1}$ Graduado em História pelo Centro Universitário Leonardo da Vinci (2015).

2 Pós-graduação em andamento em Inovação na Educação pela Universidade do Oeste de Santa Catarina (2019). Possui graduação em Ciências Biológicas pela Universidade do Oeste de Santa Catarina (2015).

${ }^{3}$ Graduado em Letras - Português e Inglês pela Universidade do Contestado (2005). Atualmente é Docente do Colégio Marista Frei Rogério.

${ }^{4}$ Mestre em Educação (2012), pela Universidade do Oeste de Santa Catarina, campus Joaçaba/SC. Docente da Universidade do Oeste de Santa Catarina, Campus de Videira.
} 
school with 8th and 9th grade students online. The proposal was based on the combination of the methodological tools of Storytelling, Stop motion and student video production. Four meetings were held in the history class with the theme of World War II. The students demonstrated a greater mastery of the learning objects after the production and presentation of the videos, as verified by the analysis of their work and the evaluation questionnaire.

Keywords: Pedagogical Methods. Learning. Public school. History.

\section{PRODUCCIÓN DE VIDEOS ESTUDIANTILES PARA UNA EDUCACIÓN INNOVADORA EN TIEMPOS DE PANDEMIA}

RESUMEN: Con la pandemia del Coronavirus, la educación enfrentó un paradigma crucial en lo que se refiere a los métodos pedagógicos. Añádase a eso la necesidad en establecer estrategias de enseñanza que posibilite un aprendizaje activo. De esa manera, el objetivo de ese relato de experiencia fue evaluar la relevancia de la producción de videos estudiantiles cómo método innovador de aprendizaje. La intervención pedagógica se realizó en un colegio público con alumnos del 8ํ y 9 o año de la enseñanza básica II, de manera online. La propuesta se basó en la unión de las herramientas metodológicas de Storytelling, Stop motion y producción de videos estudiantiles. Se realizaron cuatro encuentros en la disciplina de Historia, con la temática de la Segunda Guerra Mundial. Los alumnos demostraron mayor dominio de los objetos de aprendizaje después de la producción y presentación de los videos, lo que se verificó por el análisis de los trabajos desarrollados por ellos y por el cuestionario de evaluación.

Palabras clave: Métodos Pedagógicos. Aprendizaje. Colegio Público. Historia.

\section{A produção de vídeos no contexto escolar}

Ao escolhermos como método de intervenção pedagógica a produção de vídeos estudantis, a proposta partiu do pressuposto de que a linguagem do cinema está muito presente no cotidiano da geração atual do que nas anteriores. "Vivemos momentos diferentes na sociedade: a da geração de Gutenberg, quando o texto escrito é o espaço privilegiado do saber, e o momento das tecnologias que possibilita a cultura eletrônica" (SILVA, 2014, p. 37).

Hoje em dia, os jovens e adolescentes são uma geração que desde a infância 
tiveram contato com os vídeos por meio de computadores, videogames e celulares. Com a eclosão da internet e seus diversos aplicativos, cada vez mais o cinema e o filme entraram na vida dos alunos.

Os adolescentes passam grande parte de seu tempo diante da tela envolvidos em uma escrita teclada criativa (criando códigos apropriados ao novo suporte), espontânea e interativa. Essa leitura-escrita hipertextual dos adolescentes dirige-se a interlocutores reais mostrando-se muito significativa para seus usuários (FREITAS, 2009, p. 7).

Igualmente, a produção de vídeos tem sido uma ferramenta muitas vezes esquecida pelos professores. "Os meios audiovisuais estão na sociedade e dentro da escola. Alunos produzem mídia e trocam nas redes sociais. Essa produção, embora exista nas escolas, ainda não é muito explorada pedagogicamente" (SILVA, 2014, p. 38).

Quando se falava em utilização de filmes em sala de aula, muitas vezes os professores associavam isso a apenas passar um filme em trechos ou por completo para os alunos e depois faziam perguntas para eles relatarem oralmente ou escreverem um resumo sobre o filme.

Acredito que a mídia deve ser usada como um meio para educar, para contribuir no processo pedagógico e que ela não deve ser vista como um fim em si. A tecnologia não deve ser usada como modismo. Essa é a atitude que eu procuro conhecer na ação de professores que produzem vídeo com alunos (SILVA, 2014, p. 40).

O pensamento e crítica em relação a isso é sobre a eficácia do método. O que garante que isso produz um conhecimento necessário para que ele possa aplicar à sua vida? Desse modo, produzir vídeos é uma oportunidade relevante de reconstruir o objeto de conhecimento, seja de qual disciplina for, em um vídeo com cunho educacional.

Inúmeras habilidades e qualidades podem ser desenvolvidas a partir da prática da produção de filmes em sala de aula. Veja que não é apenas a produção de uma história contada em um vídeo, mas também pode ser uma videoaula sobre prática de exercícios físicos, uma demonstração do passo a passo de uma experiência científica, a realização de um cálculo matemático de forma lúdica etc. Essa metodologia não 
significa uma fuga dos componentes curriculares de cada disciplina, mas sim consiste em fortalecer o processo de aprendizagem (PEREIRA; JANHKE, 2012, p. 30).

Dessa forma, utilizando-se das técnicas que o cinema proporciona para a produção de filmes, aplicando-as em sala de aula, observou-se que favorece o processo de ensino e aprendizagem em uma aula, que, em outras circunstâncias, poderia ser menos eficaz se não fosse utilizada esta metodologia.

\section{Percepção dos alunos sobre as aulas remotas durante a pandemia}

A atividade de intervenção pedagógica foi realizada em uma escola pública, localizada no interior do município de Capinzal, SC. A escola, durante a pandemia, se organizou para continuar oferecendo ensino aos alunos através de aulas remotas. Os professores da Rede Municipal de Ensino receberam treinamento oferecido pela Secretaria de Educação para capacitação on-line no uso de mídias digitais e plataformas no contexto da pandemia. Participaram da atividade 18 alunos que estudam no 8ㅇ e 9ㅇ ano, sendo 10 meninas e 8 meninos, que têm entre 13 e 15 anos de idade.

No primeiro encontro on-line com os alunos, encaminhou-se um questionário no google formulários com o objetivo de verificar qual a percepção dos mesmos sobre o ensino e a aprendizagem durante o período de pandemia. Dos 18 alunos participantes, somente 13 responderam ao primeiro questionário.

Nesse período de pandemia todos estão tendo aulas on-line e quando questionados se gostavam do modo como as aulas estavam ocorrendo $100 \%$ (13) responderam que sim. Quanto à percepção deles em relação ao aprendizado obtido, $61,5 \%$ disseram que estão conseguindo aprender e 38,5\% afirmaram que acompanham as aulas, porém sentem dúvidas.

Em relação às dificuldades encontradas durante e execução das atividades propostas, 53,8\% afirmaram ter perda de atenção diante dos aplicativos e jogos disponíveis no celular ou computador, enquanto $46,2 \%$ têm outras dificuldades para realizar as atividades, porém não especificaram quais.

Com relação às dificuldades em participar das aulas, 53,8\% responderam ter problemas com a distração em relação às tarefas do lar, enquanto 30,8\% relatam ter problemas com a conexão da internet, que acaba atrapalhando e ocasionando a perda 
de concentração. Além disso, 15,4\% têm receio de realizar questionamentos ou comentários pelo chat ou áudio.

Percebeu-se que as principais dificuldades encontradas pelos alunos em relação às aulas foram com a conexão da internet, dificuldades de concentração e falta de explicação mais rica para melhor compreender os conteúdos são um empecilho que os alunos destacam, assim como manter uma rotina de organização (PIFFERO et al., 2020, p. 6).

Apesar das dificuldades, a maioria (38,5\%) afirmou que as atividades enviadas despertam o interesse em aprender, e 23,1\% mencionaram que são simples de entender e conseguem responder. Porém, 30,8\% não conseguem realizar as atividades sozinhos, isso mostra a importância de ter o acompanhamento do professor.

Baseado nisso, vale lembrar o que Freire (2002, p. 45) diz:

Sou tão melhor professor, então, quanto mais eficazmente consiga provocar o educando no sentido de que prepare ou refine sua curiosidade, que deve trabalhar com minha ajuda, com vistas a que produza sua inteligência do objeto ou do conteúdo de que falo.

Ao serem questionados sobre o momento que eram auxiliados pelo professor ao terem dúvidas, 53,8\% disseram ter conseguido entender e $46,2 \%$ sentiram que a explicação ficou incompleta ou inferior ao auxílio prestado pelo professor em sala de aula, evidenciando a falta do contato presencial. Sobre isso, vale ressaltar que o professor é indispensável na prática educativa.

O desafio do professor hoje é provocar o interesse do aluno para que ele realize as atividades, pois, de alguma forma a vontade de realizar será nele despertada. Isso acontece muitas vezes, com atividades que geram desafios ou atividades que têm relação significativa para a vida do aluno (BUENO, 2013, p. 18).

Todos sentem falta do ambiente escolar, mas a falta dos amigos diariamente é o que $84,6 \%$ dizem estar sentindo falta, enquanto $15,4 \%$ dizem que gostariam de ter a presença dos professores.

No geral, a maioria dos alunos estão satisfeitos com o formato que as aulas estão ocorrendo, pois saiu do tradicional de somente copiar conteúdo, teve aulas diferentes em novos formatos, possibilitando um aprendizado diversificado. Os alunos 
perceberam que o professor se adaptou à nova realidade e quer que o aluno continue aprendendo, como pode-se perceber nos seguintes relatos:

"O que mais gostei foi que está bem dividida as semanas para fazer os trabalhos, e que mesmo não podendo estar presente podemos aprender através das web aulas os conteúdos, tendo assim um entendimento melhor com a explicação do professor $e$ matando um pouco a saudade" (P1)

"Gostei dos professores mesmo com as mudanças e dificuldades encontradas, não pararem e continuar tentando de alguma forma ensinar e auxiliar os alunos" (P2).

"A diversificação do conteúdo, e não só escrito e copiado" (P3).

Nessa nova condição de aulas, os alunos relatam os pontos positivos que contribuíram para melhor aprendizagem, entre eles a flexibilidade dos horários das aulas, as novas metodologias utilizadas para promover o aprendizado, a autonomia que os alunos precisam ter para compreender melhor e também citam a preocupação dos professores em conseguir atender os alunos da melhor forma possível, mesmo com as inúmeras dificuldades em relação ao uso das tecnologias (PIFFERO et al., 2020, p. 7).

Com base na experiência das aulas on-line muitos falaram sobre a importância de manter as aulas diversificadas, utilizando mais os recursos tecnológicos como materiais em PDF, slides e a utilização de aplicativos, visto que a maioria possui celular, e que através desse conseguem complementar os conteúdos estudados realizando pesquisas no Google, assistindo vídeos no YouTube. Apesar das alternativas digitais auxiliarem os estudos, a maioria dos alunos diz aprender através da leitura de materiais impressos (30,8\%), fazendo trabalhos manuais $(15,4 \%)$ e praticando exercícios $(15,4 \%)$.

A utilização de diferentes recursos didáticos proporciona ao aluno um aumento significativo na aprendizagem, o incentivo do professor para conhecer e explorar os recursos disponíveis motiva o interesse para construção do conhecimento e despertar suas capacidades. Além de tornar a aula mais dinâmica é um excelente método para envolver cada vez mais o aprendiz no processo de ensino-aprendizagem (NICOLA; PANIZ, 2017, p. 375).

\footnotetext{
${ }^{5}$ Os participantes do estudo estão identificados com a letra P com índices numéricos.
} 


\section{Storytelling e Stop Motion na produção de vídeos}

A intervenção ocorreu em outubro/2020, utilizando o Google Meet para realização dos encontros de 1 hora cada, totalizando 4 horas de trabalho. A proposta de intervenção se baseou na aplicação de metodologias ativas no processo de ensino, utilizando a produção de vídeos juntamente com as ferramentas de Storytelling e Stop Motion.

Segundo Bacich e Moran (2018, p. 23), as "metodologias ativas englobam uma concepção do processo de ensino e aprendizagem que considera a participação efetiva dos alunos na construção da sua aprendizagem", e, assim, valoriza as diferentes formas que os estudantes envolvidos nesse processo utilizam para aprender melhor, considerando o seu próprio tempo, ritmo e estilo.

O Storytelling pode ser considerado uma ferramenta ou também uma arte, a arte de contar histórias. Contar histórias é uma das atividades mais antigas da humanidade, é algo que fazemos diariamente em diferentes momentos, utilizando-se de técnicas que chamem a atenção dos ouvintes (PALACIOS; TERENZZO, 2016). Nas diferentes fases da vida, com as pessoas que convivemos sempre compartilhamos histórias, é uma ferramenta de grande poder para compartilhar conhecimento (CAMARGO; DAROS, 2018, p. 178).

Storytelling é considerado uma metodologia ativa, pois faz o aluno sair da passividade a partir do momento que ele precisa se informar mais sobre o assunto que é sugerido para iniciar e desenvolver a história, precisa de argumentos, relatos estruturados para que consiga escrever de maneira adequada e detenha de forma satisfatória o conhecimento adquirido (CAMARGO; DAROS, 2018).

O Stop Motion consiste em uma técnica que usa imagens estáticas reproduzidas em sequência para animar objetos de qualquer tipo. O uso da técnica do Stop Motion exige na sua essência, pouco material e muita participação das pessoas envolvidas no processo. Isso faz com que o uso do Storytelling em conjunto com o Stop Sotion na sala de aula, torne o aluno parte do processo de aprendizagem, pois o mesmo tem a chance de dizer o quanto aprendeu e se expressar de uma forma lúdica (PRIEBE, 2011).

Stop Motion é um método e um veículo muito emocional. Há algo de especial e belo no fato de ser uma técnica antiquada, que nasceu quase ao mesmo tempo que o cinema live action (com atores). Quando você vê a construção dos bonecos, a textura 
deles, cria os sets e a luz do filme, tem a impressão de que está fazendo arte e não um negócio (BURTON, 2005).

Iniciou-se a intervenção com as boas-vindas aos participantes e breve apresentação da equipe e explicação da proposta do projeto de intervenção. No segundo encontro, foi apresentada a técnica de Storytelling e Stop Motion, mostrando como essas ferramentas podem estar presentes no dia a dia de cada um. Os alunos foram orientados através de exemplos e dicas de como poderiam fazer em casa o Storytelling e Stop Motion.

Para o Storytelling as técnicas apresentadas foram baseadas na descrição de Camargo e Daros (2018, p. 176) onde descrevem cinco elementos essenciais:

1- personagem; 2- o personagem deve ter desejos, necessidades, problemas, conflitos ou obstáculos; 3- o personagem deve superar obstáculos; 4- o personagem deve fazer escolhas; 5 - o personagem deve passar por um processo de transformação (para melhor).

Para a organização do Stop Motion após a apresentação, orientou-se os alunos a baixarem o aplicativo no celular e a criar cenas utilizando bonecos como personagens conforme sua imaginação, sendo tema livre.

Uma dica repassada para o Stop Motion foi em relação ao número de fotos, sendo necessária até 600 fotos por minuto. Para isso, tiveram que realizar pequenos movimentos a cada foto para ter uma movimentação perfeita ao final.

Solicitou-se que cada aluno desenvolvesse a atividade de casa utilizando-se das técnicas. Isso foi necessário para que fosse incentivada a prática e descobrissem as possibilidades de utilizar os recursos disponíveis, além de aprimorarem as habilidades de cada um através da execução.

Para o Storytelling, 6 alunos retornaram à atividade proposta, sendo duas baseadas no sonho do menino que queria ser jogador de futebol, enquanto 4 foram baseadas em personagens famosos, onde contaram a trajetória do início da carreira ao sucesso profissional.

Os alunos no processo de criação de narrativas desenvolvem habilidades de comunicação apropriadas à medida que aprendem a conduzir pesquisas sobre um assunto: fazer perguntas, organizar ideias, expressar opiniões e construir narrativas significativas (MORAN, 2019, p. 65). 
A metodologia Storytelling possui particularidades que permitem ao aluno ter novas experiências; é flexível, pois não segue modelos e é orgânica; se assemelha a técnicas milenárias; é organizada com metas e objetivos (LOURES, 2018, p. 25). Permite ao aluno criar habilidades com escrita, pois precisa estruturar a narrativa para que fique coerente, estimulando a criatividade, a autonomia e a autoaprendizagem (LOURES, 2018 p. 69). Desse modo, a arte do Stop Motion reflete o lado artístico do aluno:

A animação em Stopmotion está nas mãos das pessoas. Eu digo isso como um trocadilho. Como uma arte, o ato da animação em stopmotion requer que uma pessoa literalmente pegue um objeto com as mãos para the conceder vida, quadro a quadro. O outro significado é que nos últimos anos, a arte do stopmotion passou por um renascimento o que o tornou não só muito mais usado por grandes estúdios, mas também o colocou nas mãos de pessoas normais ao redor do mundo (PRIEBE, 2011, p. 17).

Para o Stop Motion, 12 alunos retornaram à atividade, conforme as orientações; utilizaram bonecos, objetos e desenhos para realizar a sequência dos movimentos; os vídeos tiveram até 30 segundos de duração.

No terceiro momento, os alunos assistiram à apresentação das principais técnicas para produção de vídeos. Em seguida a turma foi dividida em 6 grupos e cada grupo recebeu o depoimento de um sobrevivente da 2 2 Guerra Mundial que vivia em Hiroshima ou Nagasaki. Na sequência foram orientados a fazer no grupo um Storytelling com base no depoimento, após montar as cenas para fazer a sequência de fotos utilizando o aplicativo Stop Motion Studio e por último juntaram a narrativa do Storytelling e as fotos no aplicativo de edição de vídeo.

Todos os grupos conseguiram desenvolver e entregar a atividade, que foi apresentada para a turma no quarto encontro. Finalizadas as apresentações solicitouse um feedback do projeto desenvolvido, colocando as percepções e aprendizados, deixando livre para quem gostaria de fazer suas colocações. Para finalizar foi enviado o segundo questionário, pelo Google Formulários, para os alunos realizarem a avaliação do processo desenvolvido. 


\section{Limitações na utilização da produção de vídeos em sala de aula}

Durante a intervenção, vários obstáculos foram identificados. A distância física do professor para com o aluno impediu que grande parte das ações pedagógicas fossem realizadas. A situação totalmente atípica proporcionada pela pandemia de Coronavírus conduziu à necessidade do uso das redes sociais como instrumento de interação com os alunos.

Acerca disso, uma pesquisa sobre os desafios da educação durante a pandemia realizada com professores da rede pública de ensino da cidade de Belo Horizonte (MG) chegou à seguinte constatação:

[...] constatou-se que os desafios enfrentados pelos professores no modelo remoto são muitos: falta de preparo das instituições e dos professores para a utilização de ferramentas tecnológicas; acesso à internet pelos alunos que possibilitem essa modalidade de ensino, desmotivação de alunos e professores, baixo retorno por parte dos alunos, carga horária de trabalho para além da rotina do professor (OLIVEIRA; DIAS; ALMEIDA, 2020, p. 5).

Com os resultados alcançados no trecho acima citado, percebe-se o esforço do docente em rever suas estratégias pedagógicas, através do uso das TICs, aulas remotas e o ensino à distância.

Dentro das limitações, a elaboração do vídeo com a técnica de Stop Motion pode ter sido menos eficaz para alguns alunos porque certos detalhes da movimentação dos bonecos, da iluminação do local de gravação, dos ajustes em relação ao posicionamento de câmeras ficaram aquém em razão da ausência do professor e do aluno em sala de aula. Apesar dessa dificuldade, buscou-se proporcionar para eles, da melhor maneira possível, uma capacitação que fosse adequada nessa situação. Reuniões pelo Google Meet e conversas via WhatsApp possibilitaram o auxílio aos alunos quase que simultaneamente às atividades por eles realizadas.

Estimular o aluno foi outro fator limitante, pois quando o aluno acredita que é capaz de realizar determinada atividade ele consegue evoluir dentro do processo de aprendizagem, mantendo-se ainda mais motivado (BUENO, 2013, p. 18). Nesse aspecto, constatou-se que quando o aluno enviava um trecho de seu vídeo e recebia o 
feedback dos professores, esse aluno conseguia melhorar significativamente a qualidade de suas gravações, apesar da distância física entre professor e aluno.

Quanto à prática do Storytelling, as dificuldades encontradas foram percebidas principalmente quando os mesmos tiveram que transformar o relato dos sobreviventes em uma decupagem, ponto importante para a elaboração do filme porque é na decupagem que "[...] o diretor decide qual será a melhor maneira de mostrar a cena cinematograficamente, de transpor para a tela aquilo que é essencial da cena" (SOARES, 2007, p. 152). Nesse caso, trechos essenciais da narrativa poderiam ficar de fora. Para sanar essa dificuldade, os professores leram o Storytelling bem como a decupagem que eles realizaram e promoveram uma adequação, com dicas bem pontuais concernentes às cenas por eles escritas.

Em relação à edição dos vídeos pelos alunos, percebeu-se que a praticidade do uso do celular e os aplicativos gratuitos disponíveis facilitaram bastante o trabalho. Porém, uma dificuldade que percebemos nesse quesito ficou restrita à questão de exploração dos recursos que os aplicativos fornecem para um melhor resultado das gravações. Como exemplo, é válido citar os inúmeros recursos que os alunos deixaram de acessar (como trilha sonora, gravação da narração, corte de imagens e tratamento da imagem) em virtude da preocupação com a entrega do trabalho e não com a execução perfeita, caprichosa e criativa da edição.

Acerca do uso do tempo pelos alunos, constatou-se que mesmo com o prazo de mais de uma semana para a execução dos trabalhos, os alunos apresentaram problemas para organizar de maneira inteligente o tempo que eles tinham à disposição. Alguns deixaram para começar a realização do trabalho apenas a três dias da entrega, o que dificultou muito o processo criativo e o desempenho. Outros entregaram o trabalho já após o prazo estipulado, alegando dificuldades de inúmeras ordens. O uso inapropriado do tempo também pôde ser percebido em um dos grupos que deixou para providenciar os bonecos para gravação do Stop Motion no final de semana, um dia antes da entrega dos vídeos.

Entre os motivos que levam os alunos a não administrarem o tempo em função da motivação para o aprendizado apesar da diversificação de estratégias pedagógicas por parte dos docentes:

[...] verifica-se que não existe um programa estratégico por parte das escolas para lidar com o problema da desmotivação e os pais, apesar de participativos e interessados na educação dos filhos, não apresentam 
conhecimento dos mecanismos de percepção dos sintomas e depositam cegamente sua confiança no mecanismo escolar, que depende da iniciativa individual do professor, que não obedece a uma orientação pedagógica específica. (MORAES; VARELA, 2007, p. 12).

Também é importante relatar sobre a dificuldade ligada ao trabalho em grupo. Sabemos da importância da interação em grupo para o desenvolvimento dos alunos, conforme diz Vygotsky (1998, p. 75): "Todas as funções superiores originam-se das relações reais entre indivíduos humanos". Muitos tiveram dificuldades para liderar o grupo bem como delegar e cobrar em tempo hábil o cumprimento das tarefas dos demais componentes. Outro grupo específico alegou dificuldades de conexão com a internet e de quedas constantes de energia. Identifica-se nesse aspecto outra limitação recorrente em tempos de conexão digital.

Segundo Catanante (2020, p. 986) ter acesso a internet e a um equipamento seriam requisitos mínimos para que as aulas continuassem, porém para alguns alunos essa não era realidade, pois não estavam participando das aulas online por não terem o equipamento nem acesso à internet.

Quanto à técnica de Stop Motion, a principal dificuldade ficou restrita ao uso da técnica de movimentação dos personagens durante a cena, que exige atenção aos movimentos para trazer realismo a cada um dos personagens. Apesar das aulas de Stop Motion serem riquíssimas na explicação de como aplicar a técnica, notou-se que inúmeros alunos não a exploraram de maneira adequada, utilizando movimentações não tão naturais dos personagens e montagem de cenas com poucos detalhes. Isso pode ser explicado pelas palavras do diretor de cinema Tim Burton:

Às vezes, me sinto sem paciência para trabalhar com animação. Os filmes com atores são mais imediatos, você consegue ver o resultado logo em seguida; em animação, especialmente as realizadas em stopmotion, são necessárias várias semanas para se ver alguns minutos de história pronta. É preciso ser uma pessoa muito especial para lidar com o processo (BURTON, 2005).

Quanto à participação dos alunos, desde o primeiro encontro percebemos que havia muito interesse no assunto, visto que era algo totalmente novo aos olhos dos mesmos. Os questionários aplicados antes da execução da atividade bem como o questionário aplicado posteriormente indicam tal fato. Vários alunos relataram através 
do WhatsApp dos professores que gostaram muito de aprender a utilizar o celular para produção de vídeos e filmes.

Nos encontros realizados de maneira on-line, aqueles que não puderam participar em determinadas datas justificaram sua ausência, principalmente por motivos de consultas médicas ou cursos que realizavam em outros locais durante o horário. Isso não os impediu de ter contato com o conteúdo, visto que em três oportunidades distintas foram realizados encontros apenas com estes, permitindo assim que não perdessem a explicação necessária para as atividades.

Um fato muito importante em consideração é que as aulas através de salas virtuais colocam o aluno em uma passividade ainda maior do que as aulas presenciais, visto que não há esse contato direto do professor para com o aluno. Isso impede de saber se os alunos estão atentos com as explicações, slides, fala dos professores e se estão realizando outras atividades em paralelo com a aula.

Catanante (2020) em sua pesquisa sobre aulas on-line percebeu que o não aproveitamento e a não realização das atividades propostas ocorreram em função de não terem um espaço adequado para os estudos em suas casas, além de não conseguirem se concentrar devido às atividades domésticas ou por ter alguém chamando. Desse modo, é notória a dificuldade discente quanto à sua atitude perante aulas em meios digitais.

\section{As vantagens de se trabalhar com a produção de vídeos em sala de aula}

Durante a execução dos trabalhos realizados pelos alunos, eles mostraram grande interesse pela técnica de Stop Motion como ferramenta para elaboração e produção de vídeos e em sua grande maioria, não conheciam a técnica e, por conta disso, mesmo apresentando dificuldades para a execução, perceberam que era uma forma divertida e lúdica de elaborar e trabalhar com conteúdo pedagógico.

O envolvimento dos alunos com o conteúdo histórico abordado foi uma oportunidade a mais para vivenciarem um acontecimento histórico de uma maneira diferente do que acontece quando apenas se lê um texto e se responde questões em um caderno. A prática do Stop Motion amplia as possibilidades de aquisição do conhecimento de qualquer conteúdo educacional. Pensemos em situações nas quais os alunos, ao invés de apenas reproduzir em respostas prontas de um conteúdo, 
possam vivenciar determinadas cenas com vídeos curtos produzidos por eles mesmos. Isso traz mais vivacidade para a obtenção do conhecimento, gerando assim maior interesse pela produção acadêmica.

Notou-se o engajamento geral dos alunos na execução das atividades e embora tenham sido evidentes as vantagens, um dos grupos apresentou maior resistência em relação à execução dessas atividades. Os demais grupos, apesar das dificuldades enfrentadas, demonstraram animação diante de uma atividade que nunca tinham realizado. Vários alunos relataram, no questionário final, que gostariam de utilizar esta técnica para elaboração de outros trabalhos escolares posteriormente, o que demonstra que realmente compreenderam que a produção de vídeos estudantis é uma alternativa interessante de atividade pedagógica para sala de aula.

Assim, sobre a importância de envolver os alunos na produção de conteúdos, entende-se -se que os alunos devem ser instigados para que haja interesse pelos estudos, e, portanto, realizar um projeto é fundamental para isso, pois são estimulados a produzir narrativas e produções, nesse processo os alunos têm autonomia, tempo e ferramentas para pesquisas, com isso surgem os interesses, inspirações e questionamentos (LOURES, 2018).

A edição de vídeos por si só integra também elementos da área de Linguagens, visto que a parte artística é muito utilizada. O enquadramento das cenas, a produção de cenários, elaboração criativa de legendas, tratamento de imagens e outros efeitos colocam a própria educação artística dentro processo de aquisição de conhecimento na produção de vídeos estudantis. Desse modo, é imprescindível a utilização dessas técnicas para fortalecer o conhecimento dos alunos em um determinado objeto de estudo.

Quanto à decupagem, é indispensável compreender a importância da utilização dessa técnica em sala de aula no sentido de que ela ajuda os alunos a organizar ideias de maneira sistemática, auxiliando no processo de síntese de conteúdos e também de escolha de pontos chave para a aplicação de um determinado conhecimento. Uma das grandes dificuldades dos alunos atualmente é, após a leitura e interpretação do texto, fazer a síntese de pontos importantes para elaboração de novas ideias. A decupagem por si só auxilia os alunos nessa formulação, o que pode ser muito bem utilizado em disciplinas como Língua Portuguesa, por exemplo. Também ajuda no raciocínio lógico e em disciplinas que envolvam a reflexão crítica, e a sistematizar o conhecimento. 
Também ajuda na lógica, algo muito fundamental em disciplinas como a Filosofia, onde é necessário separar as ideias e argumentos para trazer sustentação para aquilo que se afirma. Por isso, a decupagem tem um papel fundamental no desenvolvimento cognitivo dos alunos quando utilizado em sala de aula.

Sobre interdisciplinaridade é preciso considerar que:

[...] há necessidade de contextualização, integração e interação entre os conhecimentos, a qual é intrínseca ao processo de aprendizado humano [...], a interdisciplinaridade pode ser pensada no contexto das práticas da Educação Básica, visando atender às novas exigências sociais, bem como favorecer a formação dos estudantes para atuarem de forma crítica e reflexiva no mundo contemporâneo (SILVA; SANTANA 2020, p. 67).

A técnica de Storytelling demonstrou ter muita eficácia na produção textual e no desenvolvimento linguístico dos alunos. Sabemos que receber um relato histórico escrito para desenvolver um outro texto possa a priori parecer um pouco repetitivo, porém demonstrou ser muito eficiente, pois a técnica de Storytelling ensina que devese incluir detalhes narrativos que inspirem, que cativem e emocionem aqueles que o leem ou ouvem, propondo mudanças, reflexões, pensamentos e decisões a partir de uma determinada história. Desse modo, auxilia muitos alunos, não somente na aquisição de um conhecimento, como também na oralidade e na agregação de conhecimentos da área de retórica e oratória.

Em seu trabalho sobre oratória em sala de aula com alunos do 50 ano Bergman (2009, p. 82) concluiu que: "utilizar essa estratégia nas atividades educacionais proporciona aos estudantes o desenvolvimento da observação crítica sobre como/quando a expressão oral se modifica e cria espaços regulares para adaptação da maneira de falar a cada situação".

No questionário apresentado aos alunos ao final da intervenção, foram feitas uma série de perguntas para compreendermos, a partir da visão deles, como foi a absorção do conhecimento adquirido através da produção de vídeo estudantis aplicados à sala de aula.

Uma das perguntas realizadas foi sobre em qual das etapas eles sentiram mais dificuldade. A maioria alegou que a gravação com Stop Motion foi a que trouxe mais dificuldades. Sobre o conhecimento adquirido com o trabalho de produção e edição de vídeos $55,6 \%$ avaliaram como ótimo. 
Ao serem questionados se eles pretendem usar os aplicativos utilizados em trabalhos de outras disciplinas, a grande maioria, ou seja, 83,3\%, afirmou que pretendem utilizar estas ferramentas em atividades de outras disciplinas. Isso demonstra que é muito importante no momento atual considerar as tecnologias como uma ferramenta indispensável para sala de aula, assim como o lápis e o caderno.

"As metodologias ativas constituem-se como alternativas pedagógicas que colocam o processo de ensino e aprendizagem nos alunos, envolvendo-os na aquisição de conhecimento por descoberta, investigação ou resolução de problemas (MORAN 2019, p. 7).

O método utilizado na produção de podcast de storytelling para o ensino de história, conseguiu relacionar emocionalmente os alunos com outros jovens das épocas históricas e permitiu que eles expressassem suas percepções iniciais sobre temáticas propostas. Isso gerou empatia com o conteúdo e personagens, despertando o desejo pelo conhecimento (LOURES, 2018 p. $62)$.

Relacionado ao conteúdo, foi perguntado aos alunos de qual modo eles achavam que melhor poderiam aprender sobre a Segunda Guerra Mundial. A grande maioria dividiu-se entre assistir filmes e produzir os próprios filmes (38,9\% cada). Isso indica que tanto a prática de elaborar um filme quanto simplesmente assistir auxilia significativamente no aprendizado.

Algo que foi essencial durante os encontros foi a ênfase dada à utilização de filmes como ferramenta educacional, pois estão presentes na vida cotidiana, ocupando um espaço tão importante na nossa compreensão de mundo que muitas vezes supera o texto escrito. Quando se elabora e se produz um filme, o sujeito compreende que o mesmo já faz parte da linguagem cotidiana. Portanto, utilizar essa ferramenta de modo educacional otimiza e potencializa a absorção do conhecimento pelos alunos muito mais do que simplesmente a leitura de um texto e a resposta direta de perguntas como no modo tradicional muitas vezes repetitivo em salas de aula.

Ao perguntar se todos os componentes do grupo se envolveram na realização do trabalho, $66,7 \%$ dos alunos disseram que todos participaram de maneira contínua. Verifica-se que os grupos, apesar das dificuldades enfrentadas para a organização e realização do trabalho, conseguiram realizar de maneira satisfatória as atividades que eles tinham para dar prosseguimento. $16,7 \%$ dos alunos alegaram que às vezes os colegas não ajudaram na realização do trabalho. 
Isso revela que a interatividade entre alunos de forma on-line precisa ainda de desenvolvimento e compreensão dinâmica de seu funcionamento. Perguntados sobre aquilo que individualmente mais os motivou, $66,6 \%$ disseram que foram as práticas do Stop Motion e do Storytelling.

Deve-se isso por envolver a questão lúdica de se trabalhar com bonecos, bem como também a oportunidade de explorar a criatividade. A liberdade criativa é importante porque proporciona engajamento na construção de uma história com o próprio estilo do aluno. Ao falarem que o Storytelling os motivou individualmente, é válido crer que a familiaridade com esse processo de produção de texto em sala de aula é a razão da escolha de boa parte dos alunos.

Perguntados sobre qual das atividades mais motivou-os como grupo, $44,4 \%$ responderam que o Stop Motion chamou mais a atenção. Isso remete à ideia de que, ao produzir algo que transforma um texto escrito em um filme, a parte lúdica permitiu a eles uma maior sensibilidade para com o processo criativo do grupo.

Inquiridos também se escolheriam, ao fazerem um novo trabalho escolar, a produção de vídeos estudantis, a maioria, ou seja, 66,7\%, disseram que escolheriam. isso demonstra que houve uma boa aceitação dos alunos em relação a essa estratégia, visto que foi algo novo e que se fez pertinente para os alunos.

Acerca dos pontos positivos que eles levantam em relação a realização da produção de vídeo estudantis, as respostas foram diversas. A seguir registra-se algumas delas:

"Nós aprendemos algo novo, não fazia ideia de que os filmes eram feitos assim, fiquei muito feliz em conhecer e fazer parte dessa experiência. Aprendemos também um assunto diferente, um aplicativo novo que podemos usar para fazer filmes do dia a dia e para os trabalhos de outras matérias" (P2).

"Aprendizado novo que pode ser usado não somente para trabalhos escolares, mas para algum outro projeto; sair da rotina de apenas ler, copiar e responder questões" (P2, P5).

"Aprendemos mais detalhadamente sobre o que aconteceu quando a bomba explodiu, pois tivemos que reproduzir em imagens, o que nos fez gravar melhor o que aconteceu" (P7).

Sobre os pontos negativos, os alunos trouxeram informações acerca das dificuldades encontradas para a realização da produção de vídeos estudantis. Dentre elas destacam-se as seguintes respostas: 
"Eu acho que foi a decupagem, porque às vezes a gente escreve uma coisa lá na decupagem e na hora de realizar o filme nem sempre conseguimos fazer do jeito que a gente escreveu não sei se é considerado ponto negativo" (P4)

"Acho que os pontos negativos seriam na hora de fazer o trabalho que deu algumas complicações, especificamente na hora de narrar, e também a internet não estava pegando muito bem na hora de assistir as web aulas" (P12).

Por fim, baseados na experiência que eles tiveram com a produção de vídeos estudantis, foram perguntados se queriam deixar sugestões para os professores que dão aula no ensino tradicional bem como aos futuros professores. Dentre as várias contribuições ressalta-se uma resposta que sintetiza a opinião dos alunos:

"Acho que é uma coisa diferente esse tipo de produção de vídeos estudantis, e é muito bom poder participar de experiências como esta, pois nós aprendemos de uma forma diferente e melhor, do que apenas ler e escrever. Para os professores que dão aulas no estilo tradicional é uma ótima opção mudar um pouco, podem optar por outras formas de ensinar o conteúdo, podemos aprender mais de uma forma divertida" (P16).

A produção de vídeos estudantis sinaliza a todos os que exercem a docência como missão de vida a abertura de novos caminhos para a aquisição integral do conhecimento pelos seus alunos.

\section{Considerações finais}

A proposta de uma educação inovadora, que mude com os pressupostos de uma educação tradicional muitas vezes baseada em apenas aulas expositivas, permeadas por atividades que os alunos apenas respondem questões de um texto, foi o interesse em participar na proposta da Pós-graduação em Inovação na Educação, oferecida pelo governo do estado de Santa Catarina, donde procedeu-se uma valiosa contribuição na formação acadêmica.

Desse modo, pode-se vislumbrar a educação de uma perspectiva totalmente diferente da qual muitos profissionais experimentam durante a carreira. A maioria dos docentes provêm de uma educação na qual o professor era o centro do processo de ensino-aprendizagem. 
Como alunos, esperava-se que eles trouxessem novos conhecimentos. Passivos, ficavam a observar, a olhar, a anotar, a ouvir, a perguntar quando possível. Hoje já se sabe que tais métodos foram úteis, porém o mundo e a sociedade mudaram e a forma de se compreender o processo de aprendizagem de uma pessoa também mudou. Hoje, é ponto pacífico que todas as experiências do indivíduo são fundamentais para um aprendizado eficaz. Desse modo, olhar com atenção e carinho o que é inovação na educação é indispensável para tornar esse processo algo relevante e cativante para cada aluno e aluna que é confiado aos professores.

Inovar na educação não é apenas fazer algo diferente apenas com a desculpa de que se está tornando a aula mais atrativa. Se fosse assim, qualquer tipo de atividade que foge ao tradicional seria aceitável no âmbito da sala de aula. Entende-se que inovar na educação é criar e estabelecer uma ponte entre o universo do aluno em sua totalidade com o objeto de conhecimento, de forma a permitir que esse objeto de conhecimento transforme positivamente a vida do aluno.

A educação inovadora deve oportunizar a compreensão de quem é o aluno, deve levar os docentes a compreenderem quais os melhores recursos e quais os melhores métodos para fazer de um objeto de conhecimento algo mais produtivo intelectualmente e socialmente para a formação de cidadãos plenamente preparados para a vida em sociedade.

\section{Referências}

BACICH, Lilian; MORAN, José (org.). Metodologias ativas para uma educação inovadora: uma abordagem teórico-prática. Porto Alegre: Penso, 2018.

BERGMANN, Leila Mury. A voz dos alunos na sala de aula: a prática da oratória. Educação Unisinos, v.13, n. 1, p. 76-83, 2009. Disponível em: https://www.redalyc.org/pdf/4496/449644448008.pdf. Acesso em: 25 abr. 2021.

BUENO, Wilson Silva. Motivação e desmotivação escolar no ensino fundamental anos finais. 2013. Monografia (Especialização em Coordenação Pedagógica) Universidade de Brasília, Brasília, 2013. Disponível em: https://bdm.unb.br/bitstream/10483/8133/1/2013_WiltonSilvaBueno.pdf. Acesso em: 23 fev. 2021. 
BURTON, Tim. Entrevista publicada no caderno de FIM DE SEMANA do Jornal Gazeta Mercantil, 2005. Disponível em: https://citacoes.in/citacoes/106668-tim-burtonpara-mim-stop-motion-e-um-metodo-e-um-veiculo-mu. Acesso em: 27 fev. 2021.

CAMARGO, Fausto; DAROS, Thuinie. A sala de aula inovadora: estratégias pedagógicas para fomentar o aprendizado ativo. Porto Alegre: Penso, 2018.

CATANANTE, Flávia; CAMPOS, Rogério Cláudio de; LOIOLA, Iraneia. Aulas on-line durante a pandemia: condições de acesso asseguram a participação do aluno?. Revista Científica Educ@ção, v. 4, n. 8, p. 977-988, 2020. Disponível em: https://periodicosrefoc.com.br/jornal/index.php/RCE/article/view/122. Acesso em: 20 abr. 2021.

FREIRE, Paulo. Pedagogia da autonomia: saberes necessários à prática educativa. São Paulo: Paz e Terra, 1996.

FREITAS, Maria Teresa de Assunção (org.). Cibercultura e formação de professores. Belo Horizonte: Autêntica, 2009.

LOURES, João Victor. Podcasts de Storytelling: A produção de narrativas históricas digitais para o ensino de história. 2018. Dissertação (Mestrado em Ensino de história) - Universidade Federal de Santa Catarina, Florianópolis, Santa Catarina, 2018. Disponível em: https://repositorio.ufsc.br/handle/123456789/198594. Acesso em: 25 fev. 2021.

MORAES, Carolina Roberta; VARELA, Simone. Motivação do aluno durante o processo de ensino aprendizagem. Revista eletrônica de educação, Londrina, UNIFIL, v. 1, n. 1, p. 1-12, 2007. Disponível em:

https://www.unifil.br/portal/images/pdf/documentos/revistas/revistaeletronica/educacao/jul-dez-2007.pdf. Acesso em: 28 fev. 2021.

MORAN, José. Metodologias ativas de bolso: Como os alunos podem aprender de forma ativa, simplificada e profunda. 1. ed. São Paulo: Editora do Brasil, 2019.

NICOLA, Jéssica Anese; PANIZ, Catiane Mazocco. A importância da utilização de diferentes recursos didáticos no ensino de biologia. InFor, Inov. Form., Rev. NEaDUnesp, São Paulo, v. 2, n. 1, p. 350-375, 2016. Disponível em:

https://ojs.ead.unesp.br/index.php/nead/article/view/infor2120167. Acesso em: 5 jun. 2021.

OLIVEIRA, Cláudia Ester de; DIAS, Maria Luiza; ALMEIDA, Rafael Santos de. Desafios do ensino remoto emergencial nas escolas públicas durante a pandemia. In: CONGRESSO NACIONAL UNIVERSIDADE, EAD E SOFTWARE LIVRE, 2020, Belo 
Horizonte. Anais [...]. Belo Horizonte, 2020. Disponível em:

http://www.periodicos.letras.ufmg.br/index.php/ueadsl/article/view/17578. Acesso em: 27 fev. 2021.

PALACIOS, Fernando; TERENZZO, Martha. O guia completo do Storytelling. Rio de Janeiro: Alta Books, 2016.

PEREIRA, Josias; JANHKE, Giovana. Produção de vídeo nas escolas: educar com prazer. Pelotas: Erdfilmes, 2012.

PIFFERO, E. L. F. et al. Um novo contexto, uma nova forma de ensinar: metodologias ativas em aulas remotas. Revista de Estudos e Pesquisas sobre Ensino Tecnológico (EDUCITEC), Manaus, v. 6, 2020. Disponível em:

http://200.129.168.14:9000/educitec/index.php/educitec/article/view/1420. Acesso em: 28 fev. 2021.

PRIEBE, Ken A. The advanced art of stop Motion. Stanford: Cengage Learning, 2011.

SILVA, Josias Pereira da. A produção de vídeo estudantil na prática docente: uma forma de ensinar. 2014. Tese (Doutorado em Educação) - Universidade Federal de Pelotas, Pelotas, 2014.

SILVA, Maria de Fátima Gomes da; SANTANA, lolanda Mendonça de.

Interdisciplinaridade nas práticas docentes de professoras da educação básica.

Imagens da Educação, Maringá, v. 10, n. 2, p. 65-79, 2020. Disponível em:

https://periodicos.uem.br/ojs/index.php/ImagensEduc/article/view/51145. Acesso em: 22 abr. 2021.

SOARES, Sérgio J. Puccinl. Documentário e roteiro de cinema: da pré-produção à pósprodução. 2007. Tese (Doutorado em Multimeios) - Instituto de Artes, Universidade Estadual de Campinas, Campinas, 2007. Disponível em:

http://repositorio.unicamp.br/jspui/bitstream/REPOSIP/285156/1/Soares_SergioJose Puccini_D.pdf. Acesso em: 28 fev. 2021.

VIGOTSKY, Lev Semenovich; COLE, Michel. A formação social da mente: o desenvolvimento dos processos psicológicos superiores. 6. ed. São Paulo: Martins Fontes, 1998.

Recebido em: jun. 2021

Aprovado em: nov. 2021 